\title{
Morphological Description of Mandibular Canal in Panoramic Radiographs of Brazilian Subjects: Association Between Anatomic Characteristic and Clinical Procedures
}

\author{
Descripción Morfológica del Canal Mandibular en Radiografías Panorámicas de Sujetos Brasileños: \\ Asociación entre Características Anatómicas y Procedimientos Clínicos
}

"Maise Mendonça Amorim; *** Cynthia Bicalho Borini;**:Sérgio Lúcio Pereira de Castro Lopes; ${ }^{* *}$ Francisco Haiter-Neto \& ${ }^{* * * * *}$ Paulo Henrique Ferreira Caria

AMORIM, M. M.; BORINI, C. B.; LOPES, S. L. P. C.; HAITER-NETO, F. \& CARIA, P. H. F. Morphological description of mandibular canal in panoramic radiographs of Brazilian subjects: Association between anatomic characteristic and clinical procedures. Int. J. Morphol., 27(4):1243-1248, 2009.

SUMMARY: Morphological and topographic knowledge of the mandibular canal is of paramount importance during dental procedures in the jaw, as structures that go through this canal must be preserved. The aim of this study was to make a morphologic and morphometrical analysis of the course and relations of the mandibular canal of adult men and women, in two different age groups. The sample was composed of 300 panoramic radiographs divided into 4 groups: Groups F1 and F2: women (ranging between 18-40 years, and over 40 years of age, respectively); Groups M1 and M2:men (ranging between 18-40 years and over 40 years of age, respectively). Seven linear vertical measurements were performed in the radiographs to describe the course of the mandibular canal, and its and relations with the anatomic structures of jaw. The horizontal position of the mental foramen and relation of proximity between the mandibular canal and the roots of the mandibular teeth were also evaluated. Statistically significant differences were observed in four of the measurements between genders. There was, however, no difference between age groups for any of the measurements. The most frequent position of the mental foramen was between the roots of the mandibular pre-molars; and the mandibular canal shows a relation of proximity to the roots of the mandibular third molar, moving gradually away from the roots of the other teeth. The results suggest that the measurements related to the mandibular canal performed in this study can be influenced by the gender but are independent of age.

KEY WORDS: Mandibular canal; Mental foramen; Mandibular foramen; Morphometry.

\section{INTRODUCTION}

The knowledge of the morphology and topography of the mandibular canal is important for performing dental interventions in the jaw, therefore it involves preservation of the anatomic structures that pass through it. In the surgical approach to the jaw, the mandibular canal is an anatomical structure used as reference (Lindh et al., 1995). Extraction of mandibular third molars, implant surgeries, orthognathic surgeries, and those to reduce and to fix of fractures in the different regions of the jaw, are examples of the procedures that can be done close to the mandibular canal, increasing the risks of injuries to the inferior alveolar nerve (TeerijokiOksa, 2002; Blaeser et al., 2003;).
Measurements relative to the position of the mandibular canal along its course in the jaw have been made by means of radiographic images, since its anatomical localization makes it impossible to take measurements directly on the bone segment without damaging it (Güler, 2005).

The mandibular foramen is a useful anatomic point for positioning the needle in inferior alveolar nerve anesthesia, and for planning surgical procedures in the mandibular ramus region. Injecting anesthetic solution in the pterigomandibular space, region where the inferior alveolar nerve is found in the mandibular foramen, is an

\footnotetext{
* University Federal of Bahia, Brazil.

** University Federal of Campinas, Brazil.

${ }^{* * *}$ University Federal of Pelotas, Brazil.
}

*****University Federal of Campinas, Brazil. 
anesthetic technique frequently used in the dental clinic. The failure indices of this technique range from $29 \%$ to $35 \%$ because of the lack of precision in locating the anatomy of this foramen (Afsar et al., 1998).

The mental foramen, the place where the mesial portion of the mandibular canal is exposed, is a reference structure with a great clinical applicability, being the place where the mentonian nerve passes through (Moiseiwitsch \& Hill, 1998). Injecting anesthetic solution in the region of this foramen allows the mentonian nerve and inferior alveolar nerve to be effectively blocked in the mandibular premolar region.

The previous knowledge of the horizontal position of the mental foramen in relation to the roots of mandibular teeth is an important reference for the preservation of this nerve during the implant surgery in the premolar area. This position was analyzed in several populations and panoramic radiography has been used for this analysis (Agthong et al., 2005).

In comparative analyses between genders or ages, morphometric study by means of panoramic radiography reveals the differences and inherent alterations in the evaluated groups, and has become a useful tool in research that analyzes the craniofacial complex development process (Akgül \& Toygar, 2002). The growth of the craniofacial complex is defined as a group of anatomical and physiological alterations that occur from the prenatal period until senility, however there are few scientific records of the craniofacial changes, which are continuous, in the adult phase. These morphologic alterations can become evident with increasing age, occurring differently between the genders (Enlow, 2002).

Therefore, morphometric analyses by panoramic radiography with the purpose of determining the possible alterations in the localization and course of the mandibular canal in relation to the age group and gender, are important for planning the dental, clinical and surgical procedures of patients in the adult phase. The objective of this study was to make a morphologic and morphometric analysis of the course of the mandibular canal and its relation with anatomical structures of the jaw, in adults of both genders, of two distinct age groups.

\section{MATERIAL AND METHOD}

A selection was made of 300 panoramic radiographs, taken of patients at the Oral Radiology Clinic of the State University of Campinas. The research was conducted with panoramic radiographs of patients of both genders (101 of men and 199 of women), divided into four groups: groups F1 and F2, composed of women between the ages of 18 and 40 years, and over 40 years of age, respectively; and groups M1 and M2 composed of men, between the ages of 18 and 40 years and over 40 years of age, respectively.

The panoramic radiographs had been taken with an Orthopantomograph model OP100 (Instrumentarium Imaging Inc., Tuusula, Finland), operating at a kilovoltage of 50 to $60 \mathrm{kVp}$. The inclusion criteria used to select the patients were as follows: the age group over 18 years of age; alveolar crest reabsorption would have to be minimum or absent; the corresponding images of the structures analyzed would have to be perfectly visible, and the panoramic radiograph image should present satisfactory quality (Wang et al., 1986).

The selected radiographs were digitized by means of a digital camera using image resolution of 5.1 Mp (Sony Digital Cybershot DSC-P93A ,Sony Electronics Inc., San Diego, the USA). The digitized images were imported by the Radioimp 1,0 software (Radiomemory, Belo Horizonte, Brazil) with specific tools for making linear and angular measurements in images in the maxillary and mandibular jaws.

Vertical linear measurements in the digitized radiographs were made, and all the distances were measured three times, with an interval of one week between each measurement. The following measurements were taken (Fig. 1):

D1 - Vertical distance of the most inferior point of the image of the inferior edge of the mental foramen to the image of the inferior limit of the mandible base.

D2 - Vertical distance of the most superior point of the image of the superior edge of the mental foramen to the image of the superior limit of the alveolar crest of the region between the mandibular premolars.

D3 - Vertical distance of the image of the inferior cortical of the mandibular canal to the inferior limit of the mandible base, in the height of the image of the anterior edge of the mandibular ramus.

D4 - Vertical distance of the image of the superior cortical of the mandibular canal to the inferior limit of the image of the oblique line in the height of the image of the anterior edge of the mandibular ramus.

D5 - Vertical distance of the most inferior point of the image 


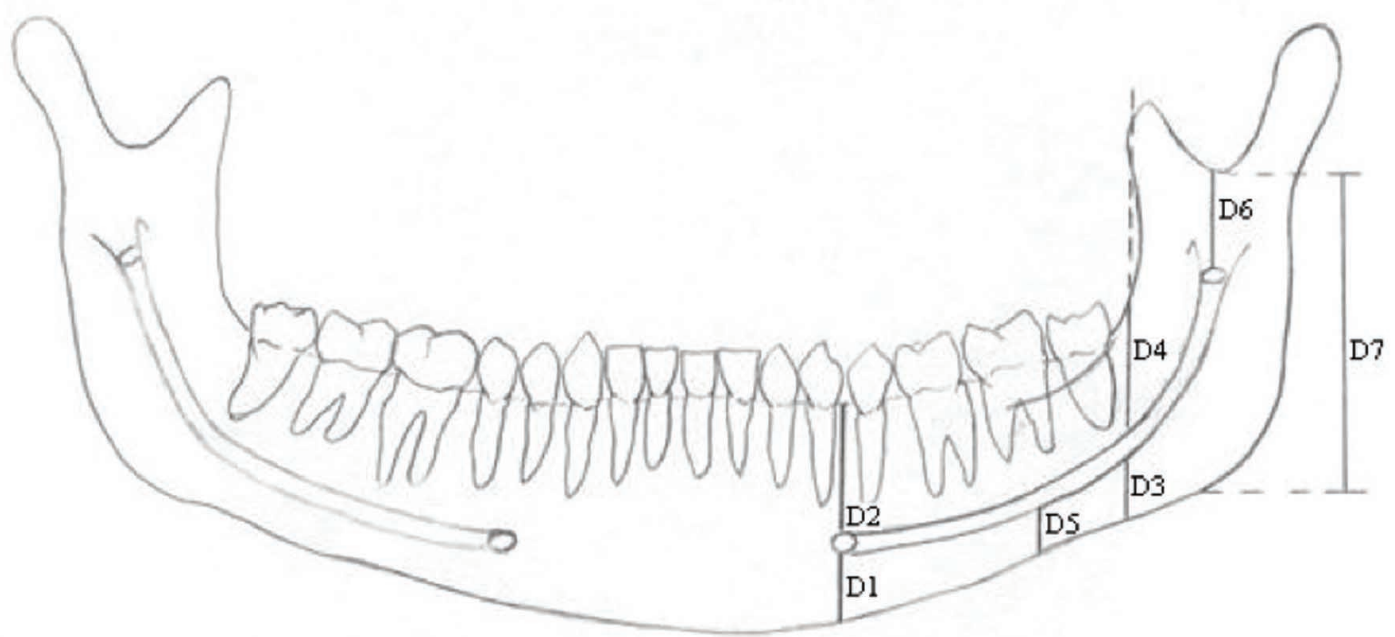

Fig. 1. Measurements made on the panoramic radiograph image.

of the inferior cortical of the mandibular canal to the inferior limit of the mandible base.

D6 - Vertical distance of the most inferior point of the image of the mandibular notch to the image of mandbular foramen.

D7 - Vertical distance of the most inferior point of the image of the mandibular notch to the image of the inferior edge of the mandibular ramus.

Based on the measurements, the following ratios were calculated: R1 - Ratio between the measurements D1 and D2; R2 - Ratio between the measurements D3 and D4; R3 - Ratio between the measurements D6 and D7.

The horizontal position of the mental foramen image in relation to the images of the mandibular tooth roots, and the relation of proximity of the mandibular canal image with the images of the roots of these teeth were also analyzed. The mental foramen image in relation to the roots of mandibular teeth was classified in accordance with 5 positions (Madeira, 2003): 1. Anterior to first mandibular premolar ; 2. Below of the apex of first mandibular premolar; 3. Between the mandibular premolars roots; 4. Below of the apex of second mandibular premolar; 5. Posterior to the second mandibular premolar.

The proximity of the image of the mandibular canal to the roots of mandibular teeth was classified in accordance with 3 types of relation (Madeira): 1. There is a relation of proximity of the mandibular canal image only with the image of the root of the mandibular third molar, and from this point, there is a gradual removal of the mandibular canal in relation to the roots of other mandibular teeth.; 2 . There is an absence of proximity between the mandibular canal and the roots of mandibular teeth; 3.There is a relation of proximity between the mandibular canal and the roots of all the mandibular teeth.

The analysis of variance was used in accordance with the adjusted model for experiments with an only factor and the Tukey test for multiple comparisons of means, as tool for comparison of the effect of the experimental groups on the variable of numerical answers. A level of significance of $5 \%$ for the statistical tests used was considered. To describe the results observed, mean, standard deviation and limits of the reliable interval of $95 \%$ were used, values that allowed the basic characteristics of the observed measurements to be described. The values of the ICC (intraclass correlation coefficient) were above 0.95 for all measurements made (Shrout \& Fleiss, 1979).

\section{RESULTS}

The results are represented in Tables I, II and III. None of the measurements was influenced by the studied age groups, however, in those where the mental and mandibular foramens were used, statistically significant differences between the genders were shown. The mean values of the ratio between the distance from the mental foramen to the mandibular base and from it to the alveolar crest can be used as a method of quantifying the original height of the alveolar crest in mandibles that had undergone bone reabsorption. 


\begin{tabular}{lcccc}
\hline & \multicolumn{4}{c}{ Groups } \\
\cline { 2 - 5 } Measurements (mm) & F1 & F2 & M1 & M2 \\
\hline D1 & $10.75 \mathrm{~A}$ & $10.62 \mathrm{~A}$ & $11.81 \mathrm{~B}$ & $11.91 \mathrm{~B}$ \\
D2 & $17.14 \mathrm{~A}$ & $16.53 \mathrm{~A}$ & $18.54 \mathrm{~B}$ & $17.44 \mathrm{~B}$ \\
R1 & $0.64 \mathrm{~A}$ & $0.70 \mathrm{~A}$ & $0.67 \mathrm{~A}$ & $0.65 \mathrm{~A}$ \\
D3 & $8.49 \mathrm{~A}$ & $8.74 \mathrm{~A}$ & $8.93 \mathrm{~A}$ & $8.80 \mathrm{~A}$ \\
D4 & $14.08 \mathrm{AB}$ & $12.45 \mathrm{~B}$ & $14.71 \mathrm{~A}$ & \\
R2 & $0.65 \mathrm{~A}$ & $0.75 \mathrm{~A}$ & $0.66 \mathrm{~A}$ & \\
D5 & $6.86 \mathrm{~A}$ & $6.87 \mathrm{~A}$ & $6.94 \mathrm{~A}$ & $7.32 \mathrm{~A}$ \\
D6 & $23.1 \mathrm{~A}$ & $23.74 \mathrm{~A}$ & $24.92 \mathrm{~B}$ & $25.07 \mathrm{~B}$ \\
D7 & $46.91 \mathrm{~A}$ & $45.41 \mathrm{~A}$ & $50.12 \mathrm{~B}$ & $48.52 \mathrm{~B}$ \\
R3 & $0.49 \mathrm{~A}$ & $0.53 \mathrm{~A}$ & $0.50 \mathrm{~A}$ & $0.52 \mathrm{~A}$ \\
\hline
\end{tabular}

\begin{tabular}{lccccc}
\hline & \multicolumn{5}{c}{ Position } \\
\cline { 2 - 6 } Groups & $\mathbf{1}$ & $\mathbf{2}$ & $\mathbf{3}$ & $\mathbf{4}$ & $\mathbf{5}$ \\
\hline F1 & 3,13 & 8,59 & 50 & 36,72 & 1,56 \\
F2 & 0 & 5,26 & 57,89 & 23,68 & 13,16 \\
M1 & 1,72 & 5,17 & 56,9 & 34,48 & 1,72 \\
M2 & 0 & 5,26 & 52,63 & 42,11 & 0 \\
\hline
\end{tabular}

\begin{tabular}{lccc}
\hline & \multicolumn{3}{c}{ Position } \\
\cline { 2 - 4 } Groups & $\mathbf{1}$ & $\mathbf{2}$ & $\mathbf{3}$ \\
\hline F1 & 76,15 & 8,46 & 15,38 \\
F2 & 62,51 & 28,13 & 9,38 \\
M1 & 74,58 & 15,25 & 10,17 \\
M2 & 68,19 & 31,82 & 0 \\
\hline
\end{tabular}

Table I. Mean values and ratio of the relative measurements of the mandibular canal course in the groups F1, F2, M1 and M2. Means with the same letters on each line do not differ among them by the Tukey test, with a level of significance of $5 \%$.

Table II. Horizontal position of the mental foramen in relation to the roots of mandibular teeth.

Table III. Proximity relation of the mandibular canal with the roots of mandibular teeth.

\section{DISCUSSION}

The mental foramen has been used as a point of reference in morphometric analyses of the mandible, by virtue of its stable relation with the base of this bone (Neiva et al., 2004). In this study, the mean values of the distances between the image of the mental foramen and the mandible base (D1), and of this foramen to the alveolar crest (D2) had no statistically significant differences between the analyzed age groups, confirming the stability of this relation throughout the individual's adult life. The mean values of R1 (D1/D2) did not differ statistically between the four studied groups indicating that it is constant. There are records in the literature that the stability of D1 not depend on the reabsorption of the alveolar process in the region above of the foramen, and that the vertical measurements in panoramic radiography are clinically applicable for quantification of the height of the alveolar bone in this region (Lindh et al.;
Güller et al.). The mean values of the ratios found in this study agree with those found by other authors, thus it contributes to validation of the method for the quantification of the extent of alveolar loss. In oral rehabilitation by means of dental implants in the mandibular premolar region, the mental foramen is the anatomic reference used to quantify the bone volume available in vertical direction. Therefore, surgical planning for this purpose can be done based in this method, reducing the risks of failure in dental implant osseointegration, and making a high level of safety and effectiveness possible for re-establishing the chewing function of these individuals. Although some authors have affirmed that this foramen is located in an average point between the alveolar crest and the mandible base (Wang et al.), the results of this study agree with other authors that showed that the mental foramen presents a position close to the mandible base (Teerijoki-Oksa et al.). 
The analysis of the present study showed that these two more common positions presented a prevalence of $88 \%$ for all the studies groups, being in agreement with the prevalence found for other authors (Neiva et al.; Lindh et al.), and suggesting that in anesthesia of the mental nerve, the anesthetic solution should be injected with the needle located in this regions, thus enabling success rates of approximately $90 \%$. In accordance with these analyses, in $10 \%$ of the cases the mental foramen is not in these usual positions. These uncommon localizations can influence the failure of mental nerve anesthesia. Dental implant surgery in this region requires special attention to the horizontal position of the mental foramen, since paresthesia is one of the most frequent complications in this type of surgery, and can be prevented when the foramen position is determined previously.

The mean values of R2 (D3/D4), both in the height of the mandibular ramus, presented no statistically significant differences between the studied groups, suggesting that this relation also remains constant throughout the individual's adult life, independent of gender. The mean values of R2 are similar to the mean values of R1. Both are approximately, 0.70 , and it indicates that during the course of the canal in the body of the mandible, it maintains constant relations between the canal/mandible base and canal/alveolar crest distances.

The image of the most inferior point of the mandibular canal is situated at the height of the second mandibular molar region. These results showed that mean values of the distances between the image of the most inferior point of the mandibular canal and the image of the base of the lower jaw presented no statistically significant differences between the four studied groups, suggesting that this distance remains stable in the adult phase, independent of gender or age group.

The distance from the image of the mandibular foramen to the image of the mandibular incisura (D6) and the image of the total length of the mandibular ramus (D7) presented no statistically significant differences in relation to the studied age groups, however, both distances were bigger in men, confirming the results founded by other authors (Afsar et al.). Nevertheless, these authors evaluated only individuals that belonged to a age group below 40 years of age, and no analyses were found the in literature analyses using panoramic radiographs of the vertical position of this foramen in individuals in the over 40-year old age group. In the present study, the ratio R3 (D6/D7) did not differ statistically between the studied groups, indicating that vertically, the foramen is in the middle portion of the mandibular ramus, at a point located approximately in the half of its length. This result is an important data for planning surgery that involves the mandibular ramus. In these cases, determining this localization helps to prevent hemorrhages and permanent damage caused by lesion to the mandibular alveolar beam. Moreover, from these mean values it can be estimated in which region the needle for the anesthesia to block this nerve must be located.

The measurements D1, D2, D6 and D7 were bigger in men, confirming the results of previous studies that affirmed that in the adult phase, the rate and speed of growth are bigger in men, with the result that craniofacial dimensions in this gender are from 5 to $9 \%$ bigger when compared with those of women (Enlow et al.). Bone growth in the adult phase can be controlled by multiple factors. Sex hormones, such as estrogen and progesterone can influence in the speed of bone growth in this phase, contributing to the development of craniofacial morphologic differences betweenthe genders. In the menopause phase, the reduction in the estrogen rate speeds up the process of bone reabsorption that cannot be compensated by the speed of corresponding bone deposition. Furthermore, the muscular tension is considered an inductive factor of bone formation, and in the mandible, the contraction of the elevating muscles during masticatory movements exerts tension throughout the mandibular ramus. In general, men have stronger masticatory muscles than the women (Wowern $\&$ Stoltze, 1980). These two factors can explain the differences found between the genders in the measurements D1, D2, D6 and D7. The measurements D3, D4 and D5 are directly related to the curvature of the mandibular canal that an individual presents, independent of variation of gender or age group, and are able to justify the absence of statistical differences between the studied groups.

The mandibular canal presented a close relation with the mandibular third molar, with a gradual removal of the roots of other mandibular teeth. This anatomic relation of proximity of the mandibular canal with the roots of the mandibular third molar can justify the index of $0.5 \%$ to $5 \%$ of risk for damage to the inferior alveolar nerve during the extraction of this tooth (Blaeser et al.).

Based on the results of this study, it was possible to conclude that panoramic radiography was efficient for making the proposed measurements. Moreover, the description of the course of the mandibular canal and its anatomical relations by means panoramic radiograph can contribute significantly to clinical and surgical planning in different areas of Dentistry.

\section{ACKNOWLEDGEMENTS}

The authors thank the National Council of Research and Development (CNPq) for financing this study. 
AMORIM, M. M.; BORINI, C. B.; LOPES, S. L. P. C.; HAITER-NETO, F. \& CARIA, P. H. F. Descripción morfológica del canal mandibular en radiografías panorámicas de sujetos Brasileños: Asociación entre características anatómicas y procedimientos clínicos. Int. J. Morphol., 27(4):1243-1248, 2009.

RESUMEN: El conocimiento morfológico y topográfico del canal mandibular es de suma importancia durante la realización de procedimientos odontológicos en la mandíbula, pués las estructuras que lo recorren deben ser conservadas. El propósito del presente estudio fue realizar un análisis morfológico y morfométrico del curso y de las relaciones del canal mandibular en adultos hombres y mujeres, en dos grupos de edades distintas. La muestra fue comprendida por 300 radiografías panorámicas divididas en 4 grupos: Grupos F1 y F2: mujeres (con rangos entre 18 y 40 años, y con más de 40 años de edad, respectivamente); Grupos M1 y M2: hombres (con rangos entre 18 y 40 años, y con mas de 40 años de edad, respectivamente). Siete medidas lineares verticales fueron realizadas en las radiografías para describir el curso del canal mandibular, y sus relaciones con las estructuras anatómicas de la mandíbula. También fueron evaluadas la posición horizontal del foramen mentoniano y la relación de proximidad entre el canal mandibular y las raíces de las piezas dentarias mandibulares. Se encontraron diferencias estadísticamente significativas entre los géneros en cuatro de las medidas tomadas. Sin embargo, no se encontró diferencia entre los grupos de edades para ninguna de las medidas. La posición más frecuente del foramen mentoniano fue entre las raíces de los premolares mandibulares; y el canal mandibular mostró una relación de proximidad con las raíces del tercer molar mandibular, alejándose gradualmente de las raíces de las demás piezas dentarias. Los resultados sugieren que las mediciones realizadas relacionadas al canal mandibular pueden ser influenciadas por el género pero son independientes de la edad.

PALABRAS CLAVE: Canal mandibular; Foramen mentoniano; Foramen mandibular; Morfometría.

\section{REFERENCES}

Afsar, A.; Haas, D. A.; Rossouw, P. E. \& Wood, R. E. Radiographic localization of mandibular anesthesia landmarks. Oral. Surg. Oral Med. Oral Pathol. Oral Radiol. Endod., 86(2):234-41, 1998.

Agthong, S.; Huanmanop, T. \& Chentanez, V. Anatomical variations of the supraorbital, infraorbital, and mental foramina related to gender and side. J. Oral Maxillofac. Surg., 63(66):800-4, 2005.

Akgül, A. A. \& Toygar, T. U. Natural craniofacial changes in the third decade of life: a longitudinal study. Am. J. Orthod. Dentofac. Orthop., 122(5):512-22, 2002.

Blaeser, B. F.; August, M. A.; Donoff, R. B.; Kaban, L. B. \& Dodson, T. B. Panoramic radiographic risk factors for inferior alveolar nerve injury after third molar extraction. J. Oral Maxillofac. Surg., 61(4):417-21, 2003.

Enlow, D. H. \& Hans, M. G. Noções Básicas sobre Crescimento Facial. $2^{\mathrm{a}}$ ed. São Paulo, Santos, 2002.

Güler, A. U.; Sumer, M.; Sumer, P. \& Biçer, I. The evaluation of vertical heights of maxillary and mandibular bones and the location of anatomic landmarks in panoramic radiographs of edentulous patients for implant dentistry. J. Oral. Rehabil., 32(10):741-6, 2005.

Lindh, C.; Peterson, A. \& Klinge, B. Measurements of distance related to the mandibular canal in radiographs. Clin. Oral Impl. Research., 6(2):96-103, 1995.

Madeira, M. C. Anatomia da Face: Bases Anátomo-Funcionais para a Prática Odontológica. $3^{\text {a }}$ ed. São Paulo, Sarvier, 2003.
Moiseiwitsch, J. R. D. \& Hill, C. Position of the mental foramen in a North American, white population. Oral Surg. Oral Med. Oral Pathol. Oral Radiol. Endod., 85(4):457-60, 1998.

Neiva, R. F.; Gapski, R. \& Wang, H. Morphometric Analysis of Implant-Related anatomy in Caucasian Skulls. J. Periodontol., 75(8):1061-7, 2004

Shrout, P. E. \& Fleiss, J. L. Intraclass Correlations: Uses in Assessing Rater Reliability. Psychol. Bull., 86(2):420-8, 1979.

Teerijoki-Oksa, T.; Jääskeläinen, S. K.; Forssel, K.; Forssel, H.; Vähätalo, K.; Tammisalo, T. \& Virtanen, A. Risk factors of nerve injury during mandibular sagittal split osteotomy. Int. J. Oral Maxillofac. Surg., 31(11):33-9, 2002.

Wang, T.; Shih, C.; Liu, J. \& Kuo, K. A clinical and anatomical study of the location of the mental foramen in adult Chinese mandibles. Acta Anat., 126(1):29-33, 1986.

Wowern, N. \& Stoltze, K. Pattern of age related bone loss in mandibles. Scand. J. Dent. Res., 88(2):134-46, 1980.

Correspondence to:

Maise Mendonça Amorim

Universidade Federal da Bahia.

Av. Olívia Flores, $n^{\circ} 3000$

Candeias 45055-090 - Vitoria da Conquista

BA - BRAZIL

Tel.(77) 34240350

Email: maisem@ufba.br

Received: 07-07-2009

Accepted: 04-11-2009 